\title{
Rapamycin synergizes with low-dose oxaliplatin in the HCT116 colon cancer cell line by inducing enhanced apoptosis
}

\author{
XUEYING LU ${ }^{1}$, HAIBO WEI ${ }^{1}$, XIAOJIN ZHANG ${ }^{1}$, WENXIN ZHENG ${ }^{1}, \mathrm{CHENG} \mathrm{CHANG}^{2}$ and JINYU GU ${ }^{2}$ \\ ${ }^{1}$ Immunology Department, Basic Medical Science College, Harbin Medical University, Heilongjiang 150081; \\ ${ }^{2}$ General Surgery Department, The Second Affiliated Hospital of Harbin Medical University, \\ Heilongjiang 150086, P.R. China
}

Received December 10, 2010; Accepted April 13, 2011

DOI: $10.3892 / \mathrm{ol} .2011 .299$

\begin{abstract}
The present study aimed to examine the combined effects of oxaliplatin (L-OHP) and rapamycin (RAPA) in the HCT116 colon cancer cell line. The growth inhibitory effect was evaluated by MTT assay as a monotherapy or combination therapy. $\mathrm{IC}_{50}$ values were determined using CalcuSyn 2.0 software. To determine the interaction of the drugs, the combination index (CI) was calculated using the Chou-Talalay method. Apoptosis was investigated using flow cytometry and Western blotting. Acridine orange staining was employed to observe morphological changes. The results showed the $\mathrm{IC}_{50}$ values of L-OHP and RAPA to be $8.35 \pm 0.78 \mu \mathrm{M}$ ( $\mathrm{r}=0.99)$ and $223.44 \pm 38.10 \mathrm{nM} \quad(\mathrm{r}=0.94)$, respectively. CI was $\leq 1$ when L-OHP was used at doses ranging from 1 to $5 \mu \mathrm{M}$ plus RAPA at a dose of $10 \mathrm{nM}$, suggesting synergistic or additive effects. CI was $\geq 1$ when $100 \mathrm{nM}$ RAPA was used in combination with low-dose L-OHP, showing additive to antagonistic effects. The combination of L-OHP $(1 \mu \mathrm{M})$ and RAPA $(10 \mathrm{nM})$ induced $19.76 \%$ Annexin V-positive cells, which was found to be higher than L-OHP $(11.45 \%, \mathrm{p}<0.01)$ or RAPA $(6.89 \%, \mathrm{p}<0.01)$ alone. The cleaved PARP protein expression levels were highest after $48 \mathrm{~h}$ of combination treatment. Acridine orange staining showed typical bright red Acidic vesicular organelles in the RAPA group, whereas the green condensed chromatin in the apoptotic bodies was found in both the L-OHP and combination groups. In conclusion, at a cytostatic concentration, RAPA was found to potentiate the anti-tumor effects of low-dose L-OHP in the HCT116 colon cancer cell by inducing enhanced apoptosis.
\end{abstract}

Correspondence to: Dr Jinyu Gu, Department of General Surgery, The Second Affiliated Hospital of Harbin Medical University, 246 Baojian Rd, Nangang, Harbin, Heilongjiang 150086, P.R. China E-mail: gujinyu@hotmail.com; guj@ccf.org

Key words: rapamycin, oxaliplatin, colon cancer, apoptosis, autophagy

\section{Introduction}

Colorectal cancer (CRC) is the second most prevalent cancer and the third leading cause of cancer deaths worldwide (1). Oxaliplatin (L-OHP)-based chemotherapeutic regimens have proven to be effective in the prevention and treatment of tumor recurrence and metastasis in CRC. However, drug toxicity remains to be clarified in the clinic (2). Efforts have focused on incorporating cytotoxic and molecularly targeted agents into chemotherapy regimens to decrease toxicity and increase efficacy (3-5).

The mammalian target of rapamycin (mTOR), an intracellular protein with a central role in the synthesis of key cellular proteins, has emerged as a significant target for anticancer therapy in various types of tumor. Phosphatidylinositol-3-kinase (PI3K)/Akt/mTOR pathway has been reported to be constitutively overexpressed in malignant tumors including CRC (6-7). Rapamycin (RAPA) is the special inhibitor of mTOR, which has demonstrated anti-tumor effects in a variety of malignancies in preclinical and clinical studies. In addition to being used as a monotherapy, RAPA and its analogs have been shown to enhance the efficacy of a number of cytotoxic chemotherapeutic agents in various types of cancer (8-11). Studies have shown that the anti-tumor mechanism of RAPA includes both apoptosis and autophagy, and its role in the fate of cancer cells remains controversial (12). The interaction between RAPA and L-OHP has yet to be clarified as the role of apoptosis and autophagy in this combination is unknown. The present study aimed to investigate whether RAPA increased the anti-tumor efficacy of L-OHP and its potential biological mechanism.

\section{Materials and methods}

Cell culture. The HCT116 human colon cancer cell line was generously provided by Professor Morito Monden of Osaka University, Japan. Cells were grown in monolayer culture in Dulbecco's modified Eagle's medium (DMEM, Sigma), supplemented with $10 \%$ fetal bovine serum, $100 \mathrm{U} / \mathrm{ml}$ penicillin, and $100 \mu \mathrm{g} / \mathrm{ml}$ streptomycin in $5 \% \mathrm{CO}_{2}$ at $37^{\circ} \mathrm{C}$. Cells in the exponential growth phase were used in all of the experiments. 
Reagents and antibodies. RAPA was obtained from Calbiochem (Gibbstown, NJ, USA) and L-OHP was from Sigma (St. Louis, MO, USA). All antibodies were obtained from Cell Signaling Technology.

MTT assay. Cell proliferation was measured using the 3-(4,5-dimethylthiazol-2-yl)-2, 5-diphenyltetrazolium bromide (MTT) assay. In brief, cells were seeded into 96-well plates at a density of $3.5 \times 10^{3}$ cells/well $(100 \mu \mathrm{l})$, and incubated for $24 \mathrm{~h}$ for sufficient attachment before drug exposure. After $48 \mathrm{~h}$ treatment with varying doses of single drug or combined therapy, $20 \mu \mathrm{l}$ of MTT (Sigma) solution $(5 \mathrm{mg} / \mathrm{ml})$ were added to each well and the plates were incubated at $37^{\circ} \mathrm{C}$ for another $4 \mathrm{~h}$. The medium was then replaced by $200 \mu \mathrm{l}$ DMSO. Absorbance at $490 \mathrm{nM}$ was measured using a 96-well format plate reader. Wells containing only DMEM and MTT were used as controls. Cell viability was determined based on the mitochondrial conversion of MTT to yellowish formazine. Each experiment was performed using six replicated wells for each drug concentration and carried out independently three times.

Dose-effect analyses. The $\mathrm{IC}_{50}$ value was determined on the basis of dose-response curves from the MTT assay. The combined effect of L-OHP and RAPA was analyzed by calculating the combination index (CI) based on the Chou-Talalay method (13). When $\mathrm{CI}<1$, the effect was synergistic and when $\mathrm{CI}=1$, the effect was additive. The effect was antagonistic when $\mathrm{CI}>1 . \mathrm{IC}_{50}$ and $\mathrm{CI}$ were calculated using CalcuSyn software (Biosoft, Cambridge, UK).

Annexin $V$ staining. Apoptosis was detected using the Annexin V-fluorescein isothiocyanate (FITC) apoptosis kit (BD Bioscience, Rockville, MD, USA) in accordance with the manufacturer's instructions. In brief, cells $\left(5 \times 10^{5}\right)$ were seeded and cultured in 10-cm dishes for $24 \mathrm{~h}$. Cells treated for $48 \mathrm{~h}$ with L-OHP, RAPA alone or in combination were collected. Untreated cells were also collected as controls. The cells were resuspended in $500 \mu \mathrm{l}$ of binding buffer, with $5 \mu \mathrm{l}$ of Annexin V-FITC and then $5 \mu \mathrm{l}$ of propidium iodide was (PI) added. The cells were then incubated at room temperature for $5 \mathrm{~min}$ in the dark and analyzed for Annexin V-FITC binding by flow cytometry (FACSort) using a fluorescein isothiocyanate (FITC) signal detector (FL1) and a PI signal detector (FL2). The cells in the FITC-positive and PI-negative fraction were regarded as apoptotic cells. Each experiment was repeated three times and reproducible results were obtained.

Western blotting. Western blotting was performed as previously described (14). Briefly, cells plated at a density of $3 \times 10^{5} / \mathrm{ml}$ in 6-well plates were exposed to L-OHP, RAPA or a combination of the two drugs for $48 \mathrm{~h}$ prior to harvest. Following centrifugation and sonication, cell extracts were clarified at $12,000 \mathrm{rpm}$ for $10 \mathrm{~min}$ at $4^{\circ} \mathrm{C}$. Protein concentrations were measured using a BCA assay. Protein samples $(30 \mu \mathrm{g})$, diluted with SDS sample buffer, were separated by $10 \%$ polyacrylamide gel electrophoresis, followed by electroblotting on a polyvinylidene difluoride membrane. After blocking in 5\% non-fat dry milk, the membrane was incubated with cleaved poly (ADP-ribose) polymerase (PARP) antibody $(1: 1,000)$ for $1 \mathrm{~h}$ at room temperature. Equal loading of the protein samples
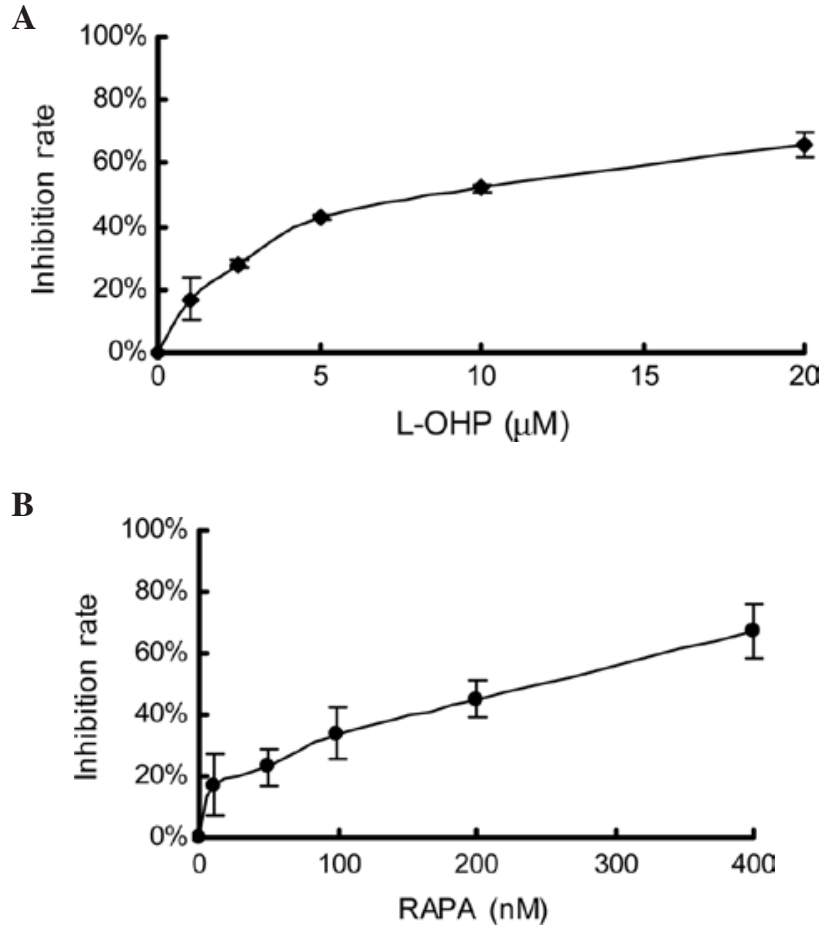

Figure 1. Growth inhibitory effect of L-OHP and RAPA in the HCT116

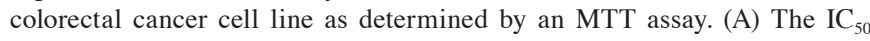
value of L-OHP calculated using CalcuSyn 2.0 software was $8.35 \pm 0.78 \mu \mathrm{m}$ $(\mathrm{r}=0.99)$. (B) $\mathrm{The} \mathrm{IC}_{50}$ value of RAPA was $223.44 \pm 38.10 \mathrm{nM}(\mathrm{r}=0.94)$. The results are shown as the mean \pm SD of triplicate samples and are representative of 3 independent experiments.

was confirmed by parallel Western blots for $\beta$-actin $(1: 1,000)$. The protein bands were detected using the ECL detection system (Pierce, Rockford, IL, USA). Each experiment was repeated three times.

Acridine orange staining. For fluorescence microscope examination, cells were seeded on glass coverslips in 24-well plates at a concentration of $1 \times 10^{4}$ cells/well. Tumor cells were treated using a single drug or a combination of both for $48 \mathrm{~h}$ and then vital staining with acridine orange was performed as previously described (15). Briefly, the treated tumor cells were stained with acridine orange at a final concentration of $1 \mu \mathrm{g} / \mathrm{ml}$ for $15 \mathrm{~min}$. Samples were examined under a fluorescence microscope. Images were obtained using a Nikon ECLIPSE 80i fluorescence microscope (exciter filter: BP 450-490 nm; barrier filter: LP $520 \mathrm{~nm}$ ).

Statistical analysis. Data are expressed as the means \pm SD and were analyzed using the Student's t-test. $\mathrm{P}<0.05$ was considered to be statistically significant.

\section{Results}

Effect of L-OHP and RAPA on cell proliferation. First, single drug-induced growth inhibition was measured using an MTT assay. The concentrations of the drugs were $1,2.5,5,10$ and $20 \mu \mathrm{M}$ for L-OHP and 10, 50, 100, 200 and $400 \mathrm{nM}$ for RAPA. After $48 \mathrm{~h}$ of treatment, an MTT assay was performed. As shown in Fig. 1, the effect of both L-OHP and RAPA was dose-dependent. The $\mathrm{IC}_{50}$ values of L-OHP and RAPA, 


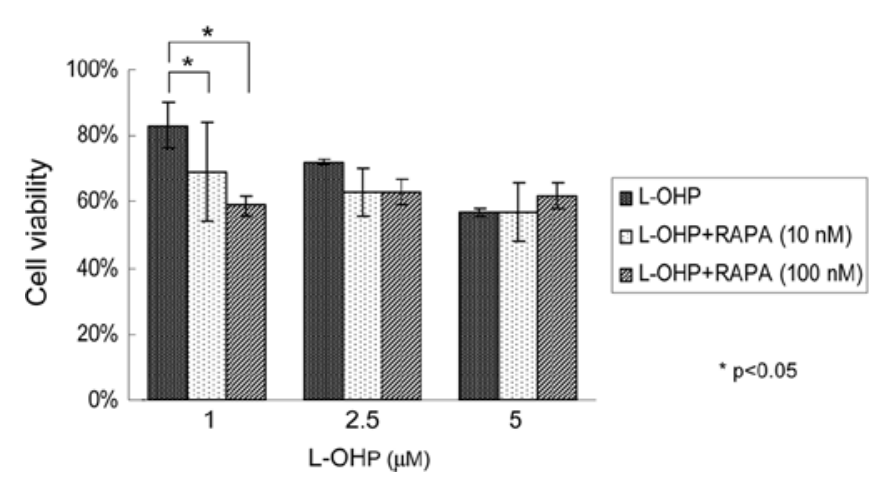

Figure 2. Cytotoxic effect of low-dose L-OHP in combination with RAPA. Cells were treated by L-OHP $(1,2.5$ or $5 \mu \mathrm{M})$ alone or in combination with RAPA (10 or $100 \mathrm{nM}$ ) for $48 \mathrm{~h}$. The results are expressed as the percentage of viable cells relative to untreated controls. The results are shown as the mean \pm SD of triplicate samples and are representative of 3 independent experiments. Statistical analysis was performed using the Student's t-test.

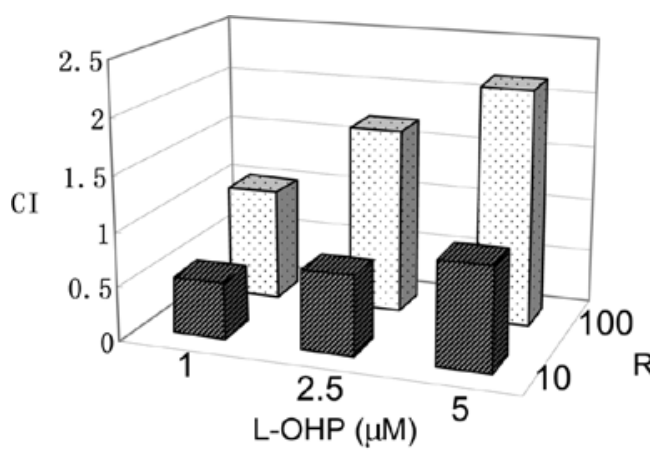

\begin{tabular}{ccc}
\hline L-OHP $(\mu \mathrm{M})$ & 10 & $\operatorname{RAPA}(\mathrm{nM})$ \\
& 0.52 & 100 \\
\hline 1 & 0.72 & 1.02 \\
2.5 & 0.95 & 1.7 \\
5 & 2.17 \\
\hline
\end{tabular}

Figure 3. Interaction between low-dose L-OHP and RAPA. CI was calculated using CalcuSyn 2.0 software based on the Chou-Talalay method (13). CI, combination index.

calculated using CalcuSyn 2.0 software, in the HCT116 colon cancer cell line were $8.35 \pm 0.78 \mu \mathrm{M}(\mathrm{r}=0.99)$ and 223.44 $\pm 38.10 \mathrm{nM}(\mathrm{r}=0.94)$, respectively.

Combination effect and interaction between low-dose L-OHP and RAPA. To test whether RAPA enhanced the anti-tumor efficacy of low-dose L-OHP, concentrations below the $\mathrm{IC}_{50}$ values of each drug were selected based on the growth inhibitory curve. The doses and their inhibitory efficacy used for the combination analysis were: $1(17 \%), 2.5(28 \%)$ and $5 \mu \mathrm{M}$ (43\%) in L-OHP, and $10(17 \%)$ or $100 \mathrm{nM} \mathrm{(34 \% )} \mathrm{in} \mathrm{RAPA.}$ Fig. 2 shows that compared with $83 \%$ cells surviving after treatment with L-OHP at a concentration of $1 \mu \mathrm{M}$ for $48 \mathrm{~h}$, the percentage of viable cells decreased to 69 and 59\% when the same dose of L-OHP was used in combination with RAPA at a concentration of 10 or $100 \mathrm{nM}(\mathrm{p}<0.05)$. To elucidate the interaction between the combinations, CI was calculated using CalcuSyn 2.0 software. As shown in Fig. 3, the CI values increased with the higher concentrations of L-OHP. CI
A

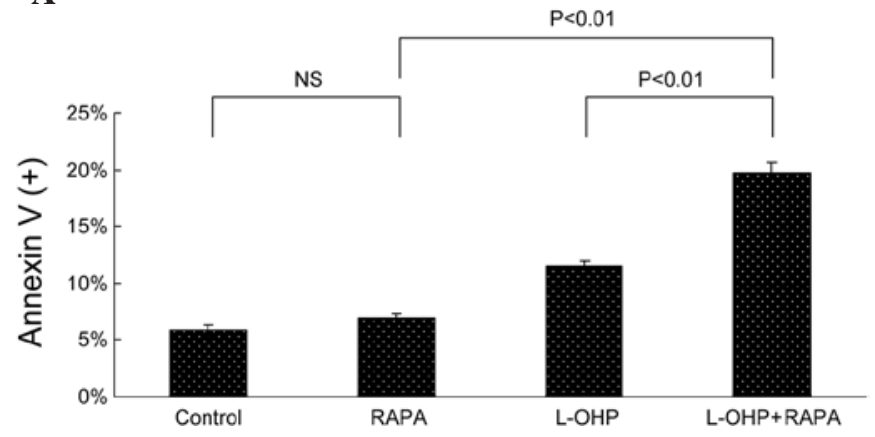

B

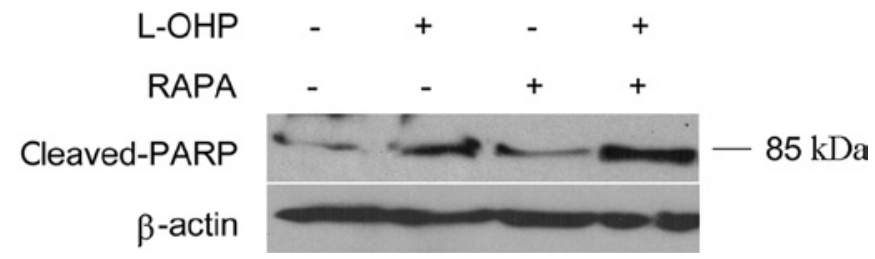

C

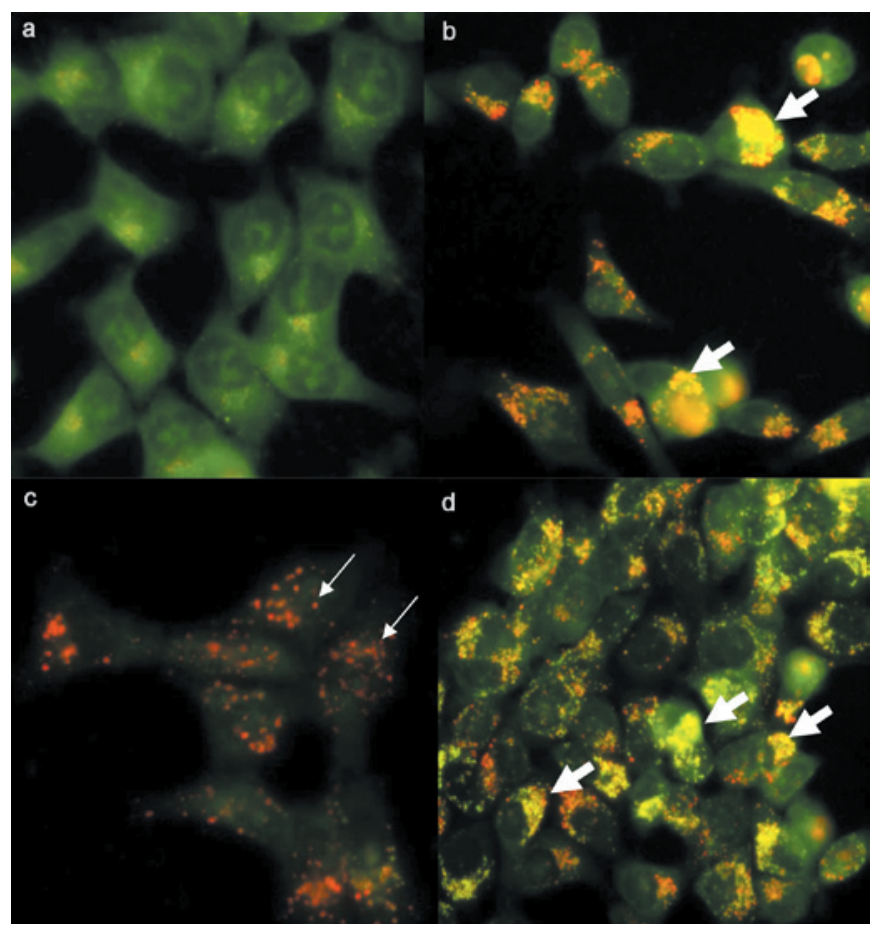

Figure 4. RAPA enhanced L-OHP-induced apoptosis. (A) Annexin V/PI flow cytometry was performed to test apoptosis in cells treated with L-OHP and RAPA individually or in combination for $48 \mathrm{~h}$. Results shown are the mean of three independent experiments. Statistical analysis was performed using the Student's t-test. (B) Western blotting was used to detect PARP cleavage after monotherapy or combined therapy after $48 \mathrm{~h}$ treatment. $\beta$-actin was used as a loading control. (C) Acridine orange staining was used to determine morphological changes. Bright red acidic vesicular organelles (AVO) (narrow arrows) was detected only in RAPA-treated cells. In the L-OHP or combination group, green condensation of chromatin in apoptotic bodies (wide arrows), a hallmark of apoptosis was revealed (magnification, $\mathrm{x} 400$ ). (a) Control group, (b) L-OHP group (1 $\mu \mathrm{M}, 48 \mathrm{~h})$, (c) RAPA group (10 nM, $48 \mathrm{~h}$ ) and (d) L-OHP+RAPA group.

was $\leq 1$ when a 1 to $5 \mu \mathrm{M}$ dose of L-OHP was combined with RAPA at a dose of $10 \mathrm{nM}$, suggesting synergistic or additive effects. CI was $\geq 1$ when $100 \mathrm{nM}$ RAPA was used with a low 
dose of L-OHP, indicating an additive to antagonistic effect. To further characterize the mechanisms of the synergy of RAPA and low-dose L-OHP combination, the combination of L-OHP at a dose of $1 \mu \mathrm{M}$ and RAPA of $10 \mathrm{nM}$ was selected for further study.

Effect of combination therapy on apoptosis and autophagy. To investigate the potential mechanisms of synergy involved in low-dose combination therapy, Annexin V/PI flow cytometry was performed first to test apoptosis. As shown in Fig. 4A, no significant difference was found in the percentage of Annexin V-positive cells between the control and RAPA groups (5.81 vs. $6.89 \%, \mathrm{p}=0.09$ ). The combination therapy induced $19.76 \%$ Annexin V-positive cells, which was higher than that of L-OHP $(11.45 \%, \mathrm{p}<0.01)$ or RAPA $(6.89 \%, \mathrm{p}<0.01)$ alone. Our results further confirmed the effect of combined therapy on apoptosis by testing PARP cleavage using Western immunoblotting. As shown in Fig. 4B, after $48 \mathrm{~h}$ treatment, RAPA induced minimal PARP cleavage, whereas the combination therapy showed the highest cleaved PARP expression. Finally, acridine orange staining was used to determine morphological changes in both apoptosis and autophagy. Autophagy is the process of isolating cytoplasmic proteins in the lytic component and is characterized by the formation and promotion of acidic vesicular organelles (AVO). Under a fluorescence microscope examination, the lysosomotropic agent acridine orange accumulating in acidic intracellular compartments appears green at low concentrations and red at high concentrations. As shown in Fig. 4C, typical bright red AVO was detected only in RAPA-treated cells. In the L-OHP and combination groups, green condensation of chromatin in apoptotic bodies, a hallmark of apoptosis, was revealed.

\section{Discussion}

In this study, we found that low-dose combination of L-OHP and RAPA synergistically inhibited HCT116 colon cancer cell growth by enhanced apoptosis in a human HCT116 colon cancer cell line. This inhibition suggested that the low-dose combination of L-OHP and RAPA is a promising effective target therapy for CRC.

Developing new therapeutic approaches with limited side-effects and favorable efficacy is crucial to cancer research. Although the side-effects of L-OHP are minimal compared with other platinum analogs, L-OHP-induced neurotoxicity often resulting in treatment delay or even cessation is the main reason of treatment failure. A recent prospective study by Park et al showed that L-OHP dose reduction or cessation as a result of neurotoxicity was required in $40 \%$ of a series of CRC patients (16). However, the pathophysiological mechanisms remain unclear and attempts to prevent neurotoxicity have been unsuccessful. Under such conditions, the synergetic effect of a low-dose combination of L-OHP $(1 \mu \mathrm{M})$ and RAPA $(10 \mathrm{nM})$ may provide alternative treatment modalities.

Results of this study showed that at a low concentration of 10 vs. $100 \mathrm{nM}$ RAPA demonstrated a synergistic interaction with low-dose L-OHP. At the concentration of $10 \mathrm{nM}$ RAPA was found not to induce significant apoptosis, consistent with its cytostatic effect on cancer cell lines, as reported recently (17-19). This result indicated the significance of using a combination of low-dose RAPA with L-OHP in the clinic, in that the combined therapy led to less toxicity and better tolerability. In a study testing a RAPA and 17-AAG combination in myeloma, Francis et al found that there was no significant difference in the synergistic effect whether RAPA was used at a concentration of 20 or $100 \mathrm{nM}$ (CI: 0.056 vs. 0.046) (20).

As with our report, the results of some studies have shown that RAPA increased chemosensitivity when combined with low-dose cytotoxic agents. In MCF-7 and MDA-MB-468 breast cancer cell lines, Mondesire et al found that low concentrations of carboplatin $(0.01 \mu \mathrm{g} / \mathrm{ml})$ or paclitaxel $(0.1 \mu \mathrm{g} / \mathrm{ml})$ alone did not induce a significant increase in apoptosis. When these drugs were combined with RAPA (10 nM), a marked increase in the percentage of Annexin V-positive cells was observed, indicative of induction of apoptosis (21). In their study on human endometrial cancer cell lines, Shafer and Bae-Jump et al demonstrated that even low doses of RAPA (1 nM) in combination with low doses of paclitaxel (0.01-0.1 $\mu \mathrm{M})$ or cisplatin $(0.01 \mu \mathrm{M})$ resulted in a strong synergistic effect by enhanced apoptosis (22-23).

Furthermore, our data suggested that the possible mechanism by which RAPA increased chemosensitivity was due to enhanced apoptosis as compared to the induction of autophagy. This observation is consistent with recent studies in breast cancer and myeloma (21-23). Autophagy or 'selfeating' is frequently activated in tumor cells treated with chemotherapy or irradiation, particularly by mTOR inhibitors. However, whether autophagy is a survival mechanism or whether it contributes to cell death remains controversial. However, the consensus is that the role of autophagy is cell type- and tumor type-specific (24). Our results suggest that autophagy induced by low-dose RAPA was not involved in L-OHP-induced apoptosis.

Our data demonstrate that the interaction between the two agents was dose-dependent. An obvious trend was evident from synergy to antagonism as drug concentration increased, indicating that complicated mechanisms were involved. Although further studies should be conducted on the effect of the combination therapy on the mTOR signal pathway to elucidate the interaction effect, the combination of low-dose L-OHP and RAPA appears to be a potential therapeutic strategy for CRC and should be investigated in vivo.

\section{Acknowledgements}

This study was funded by grants from the National Natural Science Foundation of China (No. 30700997) to Dr Xueying Lu and from the Heilongjiang overseas fund (No. LC06C27) to Dr Jinyu Gu.

\section{References}

1. Parkin DM, Bray F, Ferlay J and Pisani P: Global cancer statistics, 2002. CA Cancer J Clin 55: 74-108, 2005.

2. McWhinney SR, Goldberg RM and McLeod HL: Platinum neurotoxicity pharmacogenetics. Mol Cancer Ther 8: 10-16, 2009.

3. Gerber DE and Choy H: Cetuximab in combination therapy: from bench to clinic. Cancer Metastasis Rev 29: 171-180, 2010.

4. Rodriguez J, Zarate R, Bandres E, Viudez A, Chopitea A, García-Foncillas $\mathrm{J}$ and Gil-Bazo I: Combining chemotherapy and targeted therapies in metastatic colorectal cancer. World $\mathbf{J}$ Gastroenterol 28: 5867-5876, 2007. 
5. Wadlow RC and Ryan DP: The role of targeted agents in preoperative chemoradiation for rectal cancer. Cancer 116: 3537-3548, 2010.

6. Johnson SM, Gulhati P, Rampy BA, Han Y, Rychahou PG, Doan HQ, Weiss HL and Evers BM: Novel expression patterns of PI3K/Akt/mTOR signaling pathway components in colorectal cancer. J Am Coll Surg 210: 767-776, 2010.

7. Silvestris N, Tommasi S, Petriella D, Santini D, Fistola E, Russo A, Numico G, Tonini G, Maiello E and Colucci G: The dark side of the moon: the PI3K/PTEN/AKT pathway in colorectal carcinoma. Oncology 77 Suppl 1: 69-74, 2009.

8. Merimsky O, Gorzalczany Y and Sagi-Eisenberg R: Molecular impacts of rapamycin-based drug combinations: combining rapamycin with gemcitabine or imatinib mesylate (Gleevec) in a human leiomyosarcoma model. Int J Oncol 31: 225-232, 2007.

9. Pencreach E, Guérin E, Nicolet C, Lelong-Rebel I, Voegeli AC, Oudet P, Larsen AK, Gaub MP and Guenot D: Marked activity of irinotecan and rapamycin combination toward colon cancer cells in vivo and in vitro is mediated through cooperative modulation of the mammalian target of rapamycin/hypoxia-inducible factor-1alpha axis. Clin Cancer Res 15: 1297-1307, 2009.

10. Perotti A,Locatelli A, Sessa C,HessD, Viganò L, CapriG,MaurM, Cerny T, Cresta S, Rojo F, Albanell J, Marsoni S, Corradino I, Berk L, Rivera VM, Haluska F and Gianni L: Phase IB study of the mTOR inhibitor ridaforolimus with capecitabine. J Clin Oncol 28: 4554-4561, 2010.

11. Houghton PJ, Morton CL, Gorlick R, Lock RB, Carol H, Reynolds CP, Kang MH, Maris JM, Keir ST, Kolb EA, Wu J, Wozniak AW, Billups CA, Rubinstein L and Smith MA: Stage 2 combination testing of rapamycin with cytotoxic agents by the Pediatric Preclinical Testing Program. Mol Cancer Ther 9: 101-112, 2010

12. Eisenberg-Lerner A, Bialik S, Simon HU and Kimchi A: Life and death partners: apoptosis, autophagy and the cross-talk between them. Cell Death Differ 16: 966-975, 2009.

13. Raje N, Kumar S, Hideshima T, Ishitsuka K, Chauhan D, Mitsiades C, Podar K, Le Gouill S, Richardson P, Munshi NC, Stirling DI, Antin JH and Anderson KC: Combination of the mTOR inhibitor rapamycin and CC-5013 has synergistic activity in multiple myeloma. Blood 104: 4188-4193, 2004

14. Gu J, Yamamoto H, Lu X, Ngan CY, Tsujino T, Konishi K, Takemasa I, Ikeda M, Nagata H, Hashimoto S, Matsuzaki T, Sekimoto M, Takagi A and Monden M: Low-dose oxaliplatin enhances the antitumor efficacy of paclitaxel in human gastric cancer cell lines. Digestion 74: 19-27, 2006.
15. Paglin S, Hollister T, Delohery T, Hackett N, McMahill M, Sphicas E, Domingo D and Yahalom J: A novel response of cancer cells to radiation involves autophagy and formation of acidic vesicles. Cancer Res 61: 439-444, 2001.

16. Park SB, Goldstein D, Lin CS, Krishnan AV, Friedlander ML and Kiernan MC: Acute abnormalities of sensory nerve function associated with oxaliplatin-induced neurotoxicity. J Clin Oncol 27: 1243-1249, 2009

17. Nagata Y, Takahashi A, Ohnishi K, Ota I, Ohnishi T, Tojo T and Taniguchi S: Effect of rapamycin, an mTOR inhibitor, on radiation sensitivity of lung cancer cells having different p53 gene status. Int J Oncol 37: 1001-1010, 2010.

18. Shigematsu H, Yoshida K, Sanada Y, Osada S, Takahashi T, Wada Y, Konishi K, Okada M and Fukushima M: Rapamycin enhances chemotherapy-induced cytotoxicity by inhibiting the expressions of TS and ERK in gastric cancer cells. Int $\mathbf{J}$ Cancer 126: 2716-2725, 2010.

19. Fung AS, Wu L and Tannock IF: Concurrent and sequential administration of chemotherapy and the Mammalian target of rapamycin inhibitor temsirolimus in human cancer cells and xenografts. Clin Cancer Res 15: 5389-5395, 2009.

20. Francis LK, Alsayed Y, Leleu X, Jia X, Singha UK, Anderson J, Timm M, Ngo H, Lu G, Huston A, Ehrlich LA, Dimmock E, Lentzsch S, Hideshima T, Roodman GD, Anderson KC and Ghobrial IM: Combination mammalian target of rapamycin inhibitor rapamycin and HSP90 inhibitor 17-allylamino-17demethoxygeldanamycin has synergistic activity in multiple myeloma. Clin Cancer Res 12: 6826-6835, 2006.

21. Mondesire WH, Jian W, Zhang H, Ensor J, Hung MC, Mills GB and Meric-Bernstam F: Targeting mammalian target of rapamycin synergistically enhances chemotherapy induced cytotoxicity in breast cancer cells. Clin Cancer Res 10: 7031-7042, 2004.

22. Shafer A, Zhou C, Gehrig PA, Boggess JF and Bae-Jump VL: Rapamycin potentiates the effects of paclitaxel in endometrial cancer cells through inhibition of cell proliferation and induction of apoptosis. Int J Cancer 126: 1144-1154, 2010.

23. Bae-Jump VL, Zhou C, Boggess JF and Gehrig PA: Synergistic effect of rapamycin and cisplatin in endometrial cancer cells. Cancer 115: 3887-3896, 2009.

24. Kondo Y and Kondo S: Autophagy and cancer therapy. Autophagy 2: 85-90, 2006. 